\title{
Spirit of Inquiry of Out-of-School Youth in Rural Southern Tanzania: How Formal Schooling Shapes Receptivity of New Information to Improve Their Livelihoods
}

\author{
Daniel M. Roberts ${ }^{1}$, Douglas McFalls ${ }^{1,2, *}$, Alisha M.B. Brown ${ }^{1} \&$ Philipo Lulale Msilanga ${ }^{2}$ \\ ${ }^{1}$ College of Education, Michigan State University, East Lansing, Michigan, United States of America \\ ${ }^{2}$ African Development through Economics and the Arts (ADEA), Mtwara region, Tanzania \\ *Correspondence: College of Education, Michigan State University, East Lansing, Michigan, 48823, United States of \\ America. Tel: 1-630-520-1462. E-mail: rober697@msu.edu
}

Received: March 20, $2015 \quad$ Accepted: April 22, $2015 \quad$ Online Published: May 12, 2015

doi:10.5430/wje.v5n3p27 URL: http://dx.doi.org/10.5430/wje.v5n3p27

\begin{abstract}
Objective: Most youth in Sub-Saharan Africa are not enrolled in school. Although more youth are enrolling in school, they are increasingly less likely to complete their primary and secondary schooling. Similarly to many other African nations, Tanzania has an estimated out-of-school population of $49 \%$ of youth despite massive post-millennium investments which have significantly raised enrollment rates. Due to a high unemployment rate, rural youth commonly opt to pursue employment in cities or carry out agricultural work at home. However, their ability to procure formal employment is hindered by competition due to a high youth population density. This study sought to understand how youth with different levels of formal educational attainment (no schooling, primary schooling, secondary schooling) learn information in their community and formal schooling to improve their livelihoods and develop sustainable practices for generating income.
\end{abstract}

Methods: Through semi-structured qualitative interviews and focus group discussions, the study examines differences between the groups in what they seek to understand and the different pathways they use to learn.

Results: Although there were positive effects of schooling among the participants in this study in terms of boosting their self-confidence and self-esteem, youth dropouts with schooling experience overwhelmingly reported that they did not learn approaches and information in their schools that were beneficial for improving their livelihoods.

Conclusions: Since the majority of Tanzanian students, and particularly those from rural areas, will be unable to study in higher education institutions, educational programs for youth in school and for school dropouts are more effective which center on methods for learning new information that are applicable to their intended occupation within their community and which also prepare them for participating in the workforce.

Keywords: Tanzania; formal schooling; educational quality; out-of-school youth; sub-Saharan Africa

\section{Introduction}

Is going to school the best answer for the development of Tanzanian youth? More Tanzanian youth are enrolled in schooling than ever before. As one of the sub-Saharan African (SSA) countries adopting the fastest growth of primary completion since the turn of the millennium (Wils, Carrol \& Barrow, 2005), its net enrollment rates have increased from $53 \%$ in 2000 to $94 \%$ in 2010 for primary schooling and from $8 \%$ in 2004 to $28 \%$ in 2010 for secondary schooling for youth ages 14-19 through World Bank-funded reforms (FHI 360, 2011; World Bank, 2015). Yet, despite having an education growth rate that has increased to the present, Tanzania has an estimated out-of-school population that comprises nearly half of its youth population (Fawcett, Hartwell, \& Israel, 2010).

It is also important to recognize that net enrollment rates for primary and secondary school in Tanzania reported by the World Bank and Tanzania's ministry of education can be misleading: Tanzanian youth leave school increasingly drop out in subsequent years of their primary and secondary schooling. While a small percent of youth ages 10-14 are not enrolled $(8.3 \%)$, this rate rises drastically as youth get older, increasing to $33.8 \%$ for youth ages $15-19$ and 
$81.7 \%$ for youth ages 20-24 (Fawcett, Hartwell, \& Israel, 2010). Of the 66\% of Tanzanian youth who study in primary school, 20\% drop out before completion (United Nation's Children's Fund [UNICEF], 2011). Only half $(52.2 \%)$ of primary school leavers actually go on to enroll in secondary school and just $34.2 \%$ who enroll in secondary schooling complete it (Tanzania Ministry of Education \& Vocational Training [TMEVT], 2012]). Although Tanzania's dropout rate is relatively low in comparison to other sub-Saharan African nations, Tanzanian youth ages 15-24 not in school were estimated to comprise 49\% of its youth population ages 15 to 24 in 2007 (Fawcett, Hartwell, \& Israel, 2010).

The decision to quit school is exacerbated for impoverished Tanzanian youth. While only $40 \%$ of young men and $54 \%$ of young women from wealthier backgrounds withdraw before completing secondary schooling, the majority of low-income Tanzanian young men (87\%) and young women (92\%) drop out. A main reason for this discrepancy is that many Tanzanian youth, particularly those from disadvantaged backgrounds, leave school to pursue work opportunities. While the number of youth who leave school varies considerably by region - with rates ranging as low as $1.8 \%$ and as high as $95.9 \%$ percent (Fawcett et al., 2010; Hartwell, Wils, \& Zhao, 2006) - Tanzanian youth in rural areas generally transition to work on the family farm from an early age. Since farming in Tanzania commonly involves work with limited output, many youth migrate to urban areas. There they are more vulnerable to economic declines and weak labor demand. In comparison to older laborers, Tanzanian youth generally encounter a higher unemployment rate because the labor supply is greater than the demand (Kondyllis \& Manacorda, 2006).

\subsection{Why do Tanzanian Youth Drop out from School?}

Tanzanian youth withdraw from school for a variety of reasons. One is that Tanzanian students and their families struggle to afford school fees. When "free" primary education was introduced in Tanzania in the 1990s, more than three quarters of the costs of primary education were incurred by private households (Bray, 1996). This entails annual costs per child of approximately $\$ 85$ USD for primary school and \$90-125 USD for secondary school to pay for expenses such as a school guard, school uniforms, as well as food supplies (e.g., corn and beans) for lunch (Roberts, 2013). These expenditures, coupled with forgone opportunity costs, pose serious strains on low-income rural and urban families. This is particularly the case for poor Tanzanian youth in rural areas who can earn income at home from an early age primarily through farming or secondarily through craftsmanship and the trades.

Tanzanian youth also withdraw from school due to issues of poor educational quality in their public schools. Despite recent reforms which have boosted enrollment rates, the quality of Tanzania's educational system is still considered to be very low. Tanzanian students face numerous obstacles to receiving a quality education such as overcrowded classrooms, chronic teacher absenteeism, teacher reliance on teacher-centered rote instructional methods, a limited number of available textbooks and desks, poor sanitary conditions, and an unfriendly environment at school through using students for school labor tasks and adherence to negative behavior management strategies like corporal punishment (Davidson, 2007; Hardman, Ackers, \& Abrishamian, 2011; Osaki \& Agu, 2002; Roberts, 2013). A root cause for this is that Tanzanian teachers face major restraints in their living and work conditions due to inadequate salaries, insufficient teacher training, low teacher status, and the lack of basic resources such as water, housing, and transportation (Baker, 2011; Barrett, 2005; Vavrus \& Bartlett, 2012; Weber, 2007). Teacher performance is scantly monitored at the local ward and district education levels since there is an undefined system of accountability (Macpherson, 1999). A major consequence is that rural teachers commonly teach only a few subjects each day (Roberts, 2013; Roberts, Brown, \& Edwards, 2015). Additionally, on average, 2 teachers out of 10 are absent from school per day (Uwezo, 2013). An effect is that a large portion of Tanzanian youth enrolled in school over the age of 10 fail basic tests in Swahili (65\%), English (47\%), and mathematics (42\%), according to the most recent Uwezo (2013) assessment.

Yet, what is unprecedented in Tanzania's history is that the vast majority of Tanzanian out-of-school youth who now enter the workforce have received some schooling. For example, in the coastal southern Tanzanian region where this study was conducted, $95.9 \%$ of children had enrolled in primary school (Samji, 2010). According to human capital theory, more educational attainment leads to increased benefits such as better health and more earned income (Sweetland, 1996). In the ideal educational setting, teachers work with their students to develop a skillset that is also applicable in their life outside of school and in their jobs back at home, which in rural areas of Tanzania is farming. This study examines the extent to which personal development and the learning of new skills among out-of-school young adults in rural Mtwara is connected to their level of formal education attained.

1.2 What Skills Do Out-Of-school Youth in Tanzania Gain at School That They Can Apply to Improve Their Livelihoods as well as Their Work and Income Opportunities?

Are there specific benefits for Tanzanian youth who enroll in schooling even for a short time in terms of their ability 
to learn information which will improve their livelihoods and the effectiveness of their work activities? This question was a central focus of this study where we elicited responses from youth dropouts on how their experience both in and out of school shaped their learning of information that is directly applicable to their work environment in their communities. Though limited research has been done in this area, quantitative findings suggest that children who are not in school are much less likely to develop basic literacy and numeracy skills. Furthermore, the gap in literacy and numeracy ability between children who are in-school versus out-of-school widens over time as children get older. For example, at 7 -years $0.5 \%$ of out-of-school children passed Swahili and numeracy tests while $3 \%$ of primary school children the same age passed (Uwezo, 2013). On the same Uwezo assessments, at 16-years $19.1 \%$ of out-of-school children passed compared to $75.2 \%$ of children in public school. Thus, since out-of-school youth in particular are at risk of lower literacy and numeracy skill development, this may hinder their ability to effectively carry out tasks in the areas of accounting, research, business development, and communication.

This qualitative study incorporates focus group interviews with out of-school youth from four villages in the Mtwara region where only $62.5 \%$ of those initially enrolled completed primary school, and only half of those who pass the primary school departure exam advance to secondary school (Samji, 2010). We examine what information out-of-school youth learn and apply to improve their work and livelihoods through following interview protocols where youth with different levels of educational attainment describe the ways they learn new information. Since very limited research has examined the utility of schooling in the lives of the majority of Tanzanian youth who opt to exit before completing their last years of secondary schooling, the key contribution of the study is to gain an understanding about the ways in which education serves to benefit rural youth in their lives outside of school.

\section{Methods}

This exploratory study sought to identify and learn about the approaches that rural youth participants who are not enrolled in school use to enact change in their lives and their occupations. Since in previous research in southern Tanzania the researchers found that there is a high degree of sensitivity in being able to recruit out-of-school youth to participate in research (see Roberts et al., 2015), participants for this study were identified in rural Mtwara region villages where one of the researchers had developed trusting and lasting relationships. A qualitative approach was appropriate because we sought to gain an in-depth understanding about how the decisions out-of-school youth make to learn new information are influenced by their schooling experience or external factors such their community, government, or higher education institutions (Kutlu \& Korkmaz, 2013; Marshall \& Rossman, 1999). We employed a semi-structured format for our interviews to enable us to gain a more nuanced understanding about the processes out-of-school youth use to learn and the type of information they acquire. We elicited their reflections on the sources where they derive this information and their application of what they learned. Such an approach was also appropriate because relationships in rural areas of Tanzania are centered on social interaction. We opted not to administer surveys because in previous research we found that out-of-school youth were likely to have limited literacy skills (Roberts et al., 2015).

\subsection{Conceptual Framework}

The theoretical lens used in this study is human capital theory. Under this theory, higher educational attainment leads to the development of more skills and knowledge. As a consequence of more years of schooling, upon entry into the workforce, job tasks are performed more effectively resulting in higher economic growth. Research findings typically support human capital theory because more education has been found to lead to reductions in poverty since average earned income increases (Barro \& Lee, 2010; Cohen \& Soto, 2007; Deutsche Bank Research, 2005). Families in societies where human capital is abundant are also found to have less children and, consequently, parents invest more per child on education and health care (Becker, Murphy, \& Tamura, 1994). Conversely, no investment in education by governments may lead to increased violence, exploitation of youth populations, reduced social cohesion, and higher government spending on social welfare and crime prevention (Almendarez, 2011).

Empirical evidence also identifies a positive relationship between educational attainment and rates of return on earnings (Psacharopolous 1973, 1981, 1985). Such research has played an influential role in international pressure for Tanzania and other low-income countries to initiate educational reforms to improve access to education (Van Der Hoeven, 2012). . These reforms assume that, if we invest in education, economic and social outcomes will improve. However, Almendarez (2011) identifies that problems may arise when the education system is of poor quality, punitive, or one in which students are not gaining information which contributes to their regular skillset needed for life after school. In these cases, students may not benefit from their education through gaining more skills and knowledge. This is because student achievement depends on a given school's academic demands and the standards 
set (Coleman, Campbell, Hobson, McPartland, Mood, Weinfeld, \& York, 1966). In low-income countries, added years of education may not increase earnings or economic growth because there is a limited availability of jobs. Such predicaments can stem from regional imbalances, brain drain, or a shortage of professionals (Almendarez, 2011).

However, scant research has investigated the ways out-of-school youth in Tanzania and other low-income countries can specifically benefit from their years of schooling. This study uses human capital theory as a lens to analyze how the education provided in public schools is used in the work and lives of Tanzanian youth who do or do not have some years of schooling.

\subsection{Research Questions}

The study set out to answer the following:

1. What do rural out-of-school youth ages 17-25 in southern Tanzanian villages with differing levels of education seek to understand in their work and education and where do they derive their understandings?

2. What factors play a role in their learning of new information?

3. How do varying levels of formal education affect their ability to learn new information?

\subsection{Context of the Study}

This research took place in four rural villages (Mtimbwilimibwi, Nitekela, Nanyamba, Naputa) in Mtwara rural and Tandahimba districts, Mtwara region in southeastern Tanzania. We chose rural villages in the region of Mtwara, Tanzania because of the longstanding relationship that one of our researchers holds with the communities through his ten years of cultural work in the region with a non-governmental organization, which centered on the preservation, promotion, and perpetuation of the traditional performing arts. Mtwara lies at the Tanzanian border with Mozambique. Due to financial and time limitations, we targeted villages located two hours within the interior by car from the coastal capital city of Mtwara. Two of the villages were along the highway and two were positioned within 5-10 kilometers away from the main road. The main cash crops grown in each village were cashews, rice, peanuts, corn, and sesame. The staple crop for family consumption grown in the area was cassava. In each of the villages, Makonde language was used approximately $80 \%$ in interactions versus Swahili $20 \%$ of the time. The religious composition of each village was approximately 95\% Muslim and 5\% Christian.

\subsection{Sample Size}

Out-of-school youth in the four rural villages in Mtwara were selected for the study. As shown in Table 1, the participants consisted of 89 out-of-school youth ages 17-25 with different levels of education who were not enrolled in schooling. They were recruited by the village chairpersons and volunteered to participate in the interviews. All of the participants lived in their rural villages and primarily worked as subsistence farmers who generated income through the selling of cash crops. Exceptions were four youth ( $\mathrm{N}=2$ female; $\mathrm{N}=2$ male) who pursued work in the trades (sewing, masonry, construction) and one in music performance and composition $(\mathrm{N}=1)$. In the village of Nanyamba, out-of-school youth with some primary schooling were not available to be interviewed.

Table 1. Demographic Characteristics of the Study Group: Number of Out-Of-school Participants by Village, Schooling Level and Gender

\begin{tabular}{lcccccc}
\hline Villages & \multicolumn{2}{c}{ No schooling } & \multicolumn{2}{c}{$\begin{array}{c}\text { Some primary } \\
\text { schooling }\end{array}$} & \multicolumn{2}{c}{$\begin{array}{c}\text { Some secondary } \\
\text { schooling }\end{array}$} \\
\hline Nanyamba & $\mathrm{M}$ & $\mathrm{F}$ & $\mathrm{M}$ & $\mathrm{F}$ & $\mathrm{M}$ & $\mathrm{F}$ \\
Nitakela & 4 & 2 & 0 & 0 & 6 & 6 \\
Naputa & 4 & 3 & 3 & 3 & 6 & 6 \\
Mtimbwilimbwi & 4 & 1 & 3 & 3 & 6 & 5 \\
Total & 3 & 3 & 3 & 3 & 6 & 6 \\
& 9 & 9 & 24 & 23 & 15 & 9 \\
\hline
\end{tabular}

\subsection{Research Procedure}

In our initial visit to each of the four villages in March 2014, our objective was to recruit participants for our study. After research permits were obtained through Tanzania's Commission for Science and Technology (COSTECH) ethical protocol which also conformed to our university's Institutional Review Board's guidelines, we then visited the villages. In each village we presented a letter of approval for our study written from the Mtwara regional 
administrative secretary to the district, ward, and village leaders and made official introductions. After we received their permission to recruit participants for our study, we met with the village leaders and ngoma (drum) troop directors to explain the purpose and process of the interviews we planned to conduct in May 2014 and the number of participants we desired.

With their assistance, we recruited 30 youth ages 18-24 from each village to participate in our study and their verbal consent was attained. We then collected information about them which included their name, age, occupation, and level of schooling. Table 1 (above) presents this demographic information, illustrating that our participants were young adult men and women adults from three categories that included youth with (1) some secondary schooling experience $(n=10)$; (2) some primary schooling experience $(n=10)$ or (3) had no schooling experience $(n=10)$. The majority of initial recruits were members of the village ngoma (dance) troop who had a history of experience interacting with one of the researchers.

We then returned to the villages from May 12-19, 2014 to conduct focus group interviews. Prior to arriving, pilot interviews were conducted in Mtwara Municipal district with local Tanzanians to test the efficacy of our planned interview questions. Upon arrival, with the support of the ward and village government leaders as well as local performing group leaders, youth participants were again called on to participate. Three semi-structured focus group interviews with the three different groups of youth with different levels of educational attainment were carried out per day that were held privately in local government buildings in each village. The questions were open-ended and were centered on participants' assessments of how and where they learned new information to improve the quality of their lives and work and the influence of schooling in shaping their approaches used. All interviews were conducted in Swahili and lasted approximately 45-75 minutes.

In the first phase of the interview the questions were centered on the ways the youth have experimented with different approaches in their work (farming) or daily lives as well as methods they have seen others use to improve their livelihoods that are different than the norms practiced in their communities. The second phase of the interview was centered on questions which have emerged in their thinking about how to improve their work or living conditions to which they have sought answers and the methods they have used to explore answers to their questions. Follow-up questions were asked in order to learn more details about the respondents' rationales and thinking behind the statements they made. This allowed the research to be a process where new data could emerge (Thomas \& Thomas, 2014). Since the participants were given opportunities to engage in discourse about topics they chose, this added information which was significant to the lives of participants (Hesse-Biber \&Leavy, 2006; Strauss \& Corbin, 1998).

\subsection{Data Analysis}

Our data was transcribed and translated by a small group of educated Tanzanians. The two members of the research team who spoke Swahili fluently verified the accurateness of the translations. Our research team then analyzed the findings through coding to identify thematic areas that emerged in our interviews. Through reviewing transcriptions and field notes on an ongoing basis, a coding scheme was developed where interview responses were reduced into data groups (Creswell, 2008). To increase the internal validity of the findings, we used triangulation by testing our analytic categories, interpretations, and conclusions with interviewees from the villages where we obtained data (Lincoln \& Guba, 2000). We did this by having one of our researchers revisit the communities to discuss the text databank and preliminary themes with participants (Creswell \& Miller, 2000). Their interview responses are included to illustrate the realities of out-of-school youth's views and experiences community members' views.

\section{Results}

The following sections concentrate on the themes that emerged during the coding process. Differences are noted in the responses of participants whenever possible in order to illustrate the various learning processes taken by the out-of-school youth in this study.

\subsection{RQ3: How Do Varying Levels of Formal Education Affect the Ability to Learn New Information?}

In relation to our third research question, an important difference that emerged throughout the data collection and analysis process was that out-of-school youth with more education had significantly higher response rates in focus group discussions in comparison to those with no schooling. Specifically, behaviorally they exhibited more self-confidence and were willing to share their viewpoints, experiences, and unanswered questions they had about ways to improve their work or living conditions. In contrast, youth with no schooling infrequently expressed their individual perspectives and seldom identified questions they had to which they sought answers. This suggests that, 
despite educational quality being generally very low in Tanzanian public schools due to chronic teacher absenteeism, teacher shortages, and the lack of resources (Baker, 2011; Barrett, 2005; Davidson, 2007), schooling can still be beneficial in terms of promoting self-esteem, providing youth with appropriate inquiry skills to explore the answers to questions they have, and capacitating them to utilize communication in order to learn from others and to consider unfamiliar ideas and concepts.

\subsection{RQ2: What Factors Play a Role in the Learning of New Information?}

The primary way youth learned new information was in relation to their work within their communities, farming. All youth reported that they first learned how to farm through their immediate family, such as their parents and grandparents. When they learned non-local methods, they occasionally did so through observing neighbors and friends who were using innovative agricultural methods and conversing with them. However, the primary way that youth transitioned to other ways of farming was through consultation with agricultural professionals who came to their community such as district agricultural extension officers and staff from Naliendele Agricultural Research Institute (NARI), located in the regional capital, Mtwara. Though they may have observed non-local farming methods being used by local farmers, they reported that they typically did not make change themselves until an agricultural expert from the government or an agricultural institute instructed them to do so.

All out-of-school youth with primary and secondary experience in these villages also reported that they learned about agriculture at school because it is a required subject of Tanzania's national curriculum. However, we found scant evidence that out-of-school youth with more years of educational attainment learned non-local agricultural methods at school that were transferable to their work environment outside of school. In our interviews, youth explained that a reason for this was that they had limited interaction with local agricultural extension officers/staff since, as students, they spent the majority of their time studying at school.

An effect was that, aside from a few cases, out-of-school youth with school experience did not learn new agricultural techniques at school. This was because their school agricultural programs were centered on local farming methods. That is, they were taught methods and approaches at school that were no different than those practiced in their villages. This reality was articulated by a female secondary school dropout from Nitekela village:

We did not learn agriculture from our school. We learned how to farm from our families and neighbors in our village.

However, there were a few select cases where different agricultural knowledge and methods were learned at school. One case was out-of-school youth who had dropped out of secondary school in Mtimbwilimbwi village. They reported that a particular teacher taught them non-traditional farming methods. This included learning how to measure the correct spacing between plants and how to apply fertilizer, as described by a male Mtimbwilimbwi secondary school dropout:

Our teacher taught us that when you plant certain crops you should place fertilizer in a hole you dug a certain distance across in diameter. She told us to teach our families to do this. After that I taught my parents.

Another exception was in Nitekela village where a secondary school agricultural coordinator facilitated an agricultural program at her school. This teacher called on her students to do hands-on work during school hours where they were engaged in learning farming methods not practiced in their community. As a result, the youth with secondary school education reported that they now understood the benefits of composting as well as measuring the appropriate space between the planting of their crops. They were now applying such methods in their own farms, as described by a female secondary school dropout:

We learned how to measure in school and also how to leave the branches and leaves from our plants in a pile. This can be used as soil to plant in later on. Other farmers do not do this in our village.

These examples illustrate the potential for learning innovative agriculture methods in Tanzanian schools when teachers give demonstrations, use hands-on instructional methods, and teach a curriculum where students learn material that is directly applicable to their lives outside of school.

3.3 RQ1: What Do Rural Out-of-school Youth Seek to Understand in Their Work and Education and Where Do They Derive Their Understandings?

In relation to our first research question, when out-of-school youth opted to learn new information, they overwhelmingly sought to learn about how to improve the effectiveness of their work. This pertained to agriculture since most of the participants in these villagers were farmers. 
Within school there were only a few cases where out-of-school youth stated that they learned non-indigenous methods for improving their farming and increasing yields. A surprising finding from our study was that the majority of out-of-school youth reported that they learned non-indigenous agricultural skills through their interactions outside of school. Some reported that this was because that they had more available time to consult with experts and to observe innovative approaches used by neighbor farmers. These experiences proved to be more valuable in terms of their learning of new methods which could increase their yields and generate income. The agricultural methods that they were applying as a result of these interactions included planting in rows with measured spacing between crops and appropriate application of pesticides and fertilizers. For example, in Mtwimbwilimbwi village, youth with no schooling learned about measured spacing between plants and how to apply natural pesticides and fertilizer through attending the region's annual agricultural fair.

Another example is Nitekela village where non-schooled youth learned to apply natural and store-bought fertilizer and about the importance of spacing between crops. It was reported that they learned this through one young female non-schooled adult who was selected as a leader to represent the village in studying at Naliendele Agriculture Research Institute in Mtwara for three months. There she consulted with experts and learned different agricultural techniques, such as how to single-cross hybrid lemons and oranges. It was confirmed that she taught others in the village these methods when she returned.

One other surprising finding was that the majority of youth with no schooling in the village of Naputa had learned about problems encountered when opting to burn their own fields. This information was derived from neighborhood farmers who practiced composting. As a consequence of their exposure, these youth reported that they now composted crop residue instead of burning their fields, like this male out-of-school youth explained:

\section{We do not burn our fields because fire prevents our soils from being fertile.}

This was in contrast to the majority of out-of-school youth with some schooling experience who burned their fields. In all but a few cases, young adults with some secondary schooling experience in all villages reported that they still chose to adhere to traditional slash \& burn agricultural methods in their farming. They explained that composting was more risky since it involved waiting for up to three years for decomposition to occur; this was too long to wait. Burning their fields also served to protect their villages from wild animals such as snakes and lions, as illustrated in this statement given by a female farmer in Nitekela:

We use fire to prepare our fields because that is the tradition in our village. We have to use fire because our fields are in the forest.

Young adults with no schooling in other villages also chose to burn their fields because such an approach was viewed to be an inexpensive and time efficient way to clear their fields.

These variations illustrate that the learning of different agricultural techniques can happen in and out of school. Out-of-school youth who take the initiative can learn different farming techniques through informal opportunities available outside of school. Students in school can and do learn new techniques when they are provided with instruction from a motivated teacher or experts. The extent to which they learn in either context depends on one's own motivation as well as the expertise and resources available within a given community.

\section{Discussion}

In the context of rural Tanzania, like other sub-Saharan African contexts, this study's findings reveal that the education being taught in schools may frequently be of no direct relevance to the working lives that students will engage in when leaving school. Although there were positive effects of schooling among the participants in this study in terms of boosting their self-confidence and self-esteem, youth dropouts with schooling experience generally reported that they did not learn approaches and information in their schools which were beneficial for improving their livelihoods. This is particularly problematic because these students are also likely to have low literacy and math levels due to the poor quality of their academic learning within their schools (Uwezo, 2013). Their lack of learning such skills may pose serious obstacles in their future jobs in terms of their ability to compute basic math calculations, comprehend information being disseminated in writing, keep basic records of all transactions and new information learned, and to communicate effectively with others through correspondence.

However, despite the low quality of education in Tanzanian public schools, our findings show that even some years of schooling is beneficial. First, it teaches students how to be engaged citizens through not being afraid to ask questions and willing to communicate openly. By being more willing to participate in a dialogue, more opportunities are provided to gain new information. This prepares youth to be open to learning skills that can improve their 
livelihoods as well as catalyze development within their communities such as proficiency in agro-business, using technology, or adapting innovative methods through another means of employment.

This study's findings also illustrate that the "act of doing" has a strong impact on behavior change. For example, being an active participant, discussant, and hands-on observer of non-local farming methods had a stronger influence on behavior change for the participants within this study than the current educational approach in Tanzanian public schools, which is for agricultural education to be taught abstractly. Since the majority of Tanzanian students, and particularly those from rural areas, will be unable to study in higher education institutions, educational programs for youth in school and for school dropouts are more effective which center on methods for learning new information that are applicable to their intended occupation within their community and which also prepare them for participating in the workforce.

In rural schools the "act of doing" can be introduced to students through infusing non-local agricultural methods with school subject learning (e.g., mathematics, literacy, science). Through using such an approach, students learn skills included on the national curriculum like basic computation and reading skills which can also be transferable to their work environment outside of school. At the same time, they are also being given the opportunity to gain practical skills in agriculture and other relevant local occupations that can improve their livelihoods.

One way of doing this is partnering with district and ward agricultural extension officers as well as regional agricultural institutions. Strategies could be developed for promoting student and community learning through classroom instruction, hands-on learning on school farms, and demonstrations where community members can also learn such techniques. Through engaging in such a process, youth have the potential to develop individualized methods for lifelong learning where they use research and experimentation to identify and practice effective methods for improving their livelihoods. The development of such processes may inculcate the next generations to embark on such processes for their own learning and development.

\section{Acknowledgement}

This material is based upon work supported by the Tanzania Partnership Program Foundation via Michigan State University and funds from the John A. Hannah Chair at Michigan State University. Any opinions, findings, and conclusions or recommendations expressed in this material are those of the authors and do not necessarily reflect the views of the funding agencies.

\section{References}

Almendarez, L. (2010). Human Capital Theory: Implications for Educational Development. Second Conference of Belize Country Conference November, 2010. University of West Indies, Kingston, Jamaica.

Baker, T. (2011). Restoring Teacher Dignity, Volume II: Teaching Materials and Housing. Dar es Salaam, Tanzania: HakiElimu.

Barrett, A. M. (2005). Teacher accountability in context: Tanzanian primary school teachers' perceptions of local community and education administration. Compare, 35(1), 43-61. http://dx.doi.org/10.1080/03057920500033530

Barro, R. J., \& Lee, J. W. (2013). A new data set of educational attainment in the world, 1950-2010. Journal of Development Economics, 104, 184-198. http://dx.doi.org/10.1016/j.jdeveco.2012.10.001

Becker, G. S., Murphy, K. M., \& Tamura, R. (1994). Human capital, fertility, and economic growth. In G. S. Becker (Ed.), Human Capital: A Theoretical and Empirical Analysis with Special Reference to Education (3rd Edition) (pp. 323-350), Chicago, IL: The University of Chicago Press.

Bergheim, S. (2005). Human Capital is the Key to Growth-Success Stories and Policies for 2020. Retrieved from www.dbresearch.com/PROD/DBR_INTERNET_EN-PPROD/PROD0000000000190080.PDF

Bray, M. (1996). Counting the Full Cost: Parental and Community Financing of Education in East Asia. Washington, DC: The World Bank \& UNICEF. http://dx.doi.org/10.1596/0-8213-3827-7

Cohen, D., \& Soto, M. (2007). Growth and human capital: Good data, good results. Journal of Economic Growth, 1(3), 113-207. http://dx.doi.org/10.1007/s10887-007-9011-5

Coleman, J. S., Campbell, E. Q., Hobson, C. J., McPartland, J., Mood, A. M., Weinfeld, F. D., \& York, R. (1966). Equality of educational opportunity. Washington, DC: United States Department of Health, Education, and 
Welfare.

Creswell, J. (2008). Educational research: Planning, conducting, and evaluating quantitative and qualitative research. Upper Saddle River, NJ: Pearson Prentice Hall.

Creswell, J. W., \& Miller, D. L. (2000). Determining validity in qualitative inquiry. Theory into Practice, 39(3), 124-130. http://dx.doi.org/10.1207/s15430421tip3903_2

Davidson, E. (2007). The pivotal role of teacher motivation in Tanzanian education. Educational Forum, 71(2), 157-166. http://dx.doi.org/10.1080/00131720708984928

Fawcett, C., Hartwell, A., \& Israel, R. (2010). Out-of-school youth in developing countries: What the data do (and do not) tell us. Washington, DC: USAID \& EQUIP3.

FHI $360 \quad$ (2011). World Development Indicators. $\quad$ Retrieved from http://www.epdc.org/sites/default/files/documents/Tanzania_coreusaid.pdf

Hartwell, A., Wils, A., \& Zhao, Y. (2006). Reaching out-of-school Children: Sub-regional Disparities. Journal of Education for International Development, 2(2), 1-23.

Hesse-Biber, S., \& Leavy, P. (2006). The practice of qualitative research. Thousand Oaks, CA: Sage.

Kondylis, F., \& Manacorda, M. (2008). Youth in the Labor Market and the Transition from School to Work in Tanzania. In M. Garcia \& J. Fares (Eds.), Youth in Africa's Labor Market (pp. 225-261), Washington, DC: The World Bank. http://dx.doi.org/10.1596/978-0-8213-6884-8_ch10

Kutlu, M. O., \& Korkmaz, S. (2013). The teacher attitudes toward the learner control strategy. New World Science Academies, 8(2), 225-231. http://dx.doi.org/10.12739/NWSA.2013.8.2.1C0583

Lincoln, Y. S., \& Guba, E. (2000). Paradigmatic controversies, contradictions and emerging confluences. In Denzin, N. K. \& Lincoln, Y. S. (Eds.), Handbook of Qualitative Research (2 ${ }^{\text {nd }}$ ed.), (pp. 163-168). London: Sage.

Macpherson, R. J. S. (1999). Building a communitarian policy of educative accountability using a critical pragmatist epistemology. Journal of Educational Administration, $\quad 37(3), \quad 273-295$. http://dx.doi.org/10.1108/09578239910275508

Marshall, C., \& Rossman, G. B. (2010). Designing Qualitative research. Thousand Oaks, CA: Sage Publications.

O-saki, K. M., \& Agu, A. O. (2002). A study of classroom interaction in primary schools in the United Republic of Tanzania. Prospects, 32(1), 103-116. http://dx.doi.org/10.1023/A:1019713014049

Psacharopoulos, G. (1981). Returns to education: An updated international comparison. Comparative education, 17(3), 321-341. http://dx.doi.org/10.1080/0305006810170308

Psacharopoulos, G. (1985). Returns to education: A further international update and implications. The Journal of Human Resources, 20(4), 583-604. http://dx.doi.org/10.2307/145686

Psacharopoulos, G., \& Hinchliffe, K. (1973). Returns to education: An international comparison. San Francisco: Jossey-Bass.

Roberts, D. (2013). "Diversity of opinion in the face of prevailing practices: Schooling and school cultivation in two Tanzanian villlages," Ph.D. Dissertation, Michigan State University, Lansing, Michigan.

Roberts, D., Brown, A., \& Edwards, L. (2015). Participatory Action Research in a Rural Tanzanian village: An exploration of the $\mathrm{f}$ factors for how changes in teaching and learning practices in primary schools can be cultivated. Educational Action Research. http://dx.doi.org/10.1080/09650792.2015.1009925

Samji, W. K., Nsa, K., \& Albee, A. (2010). Energy, jobs and skills: A rapid assessment in Mtwara, Tanzania (Vol. 19). Dar es Salaam: Research on Poverty Alleviation.

Schultz, T. W. (1963). The Economic Value of Education. New York: Columbia University Press.

Strauss, A., \& Corbin, J. (1998). Basics of qualitative research: Techniques and procedures for developing grounded theory. Thousand Oaks, CA: Sage.

Sweetland, S. R. (1996). Human capital theory: Foundations of a field of inquiry. Review of Educational Research, 66(3), 341-359. http://dx.doi.org/10.3102/00346543066003341

Tanzania Ministry of Education \& Vocational Training (2012). Joint Education Sector Review. Dar es Salaam: Tanzania Ministry of Education \& Vocational Training. 
Thomas, C. \& Thomas, M. A. (2014). Zambian teachers' perceptions of expert teaching: Resourcefulness, punctuality, and sobriety. International Journal of Qualitative Studies in Education, 25(5), 583-600. http://dx.doi.org/10.1080/09518398.2011.605077

UNICEF (2011). Adolescence in Tanzania. Dar es Salaam, Tanzania: UNICEF.

Uwezo (2014). Are Our Children Learning? Literacy and Numeracy Across East Africa. Nairobi, Kenya: Hivos/Twaweza.

Van Der Hoeven, R. (2012). MDGs Post 2015: Beacons in turbulent times or false lights? New York, NY: UN System Task Team on the Post 2015 UN Development Agenda.

Vavrus, F., \& Bartlett, L. (2012). Comparative pedagogies and epistemological diversity: social and materials contexts of teaching in Tanzania. Comparative Education Review, 56(4), 634-658. http://dx.doi.org/10.1086/667395

Weber, E. (2007). Globalization, "glocal" development, and teachers' work: A research agenda. Review of Educational Research, 77(3), 279-309. http://dx.doi.org/10.3102/003465430303946

Wils, A., Carrol, B., \& Barrow, K. (2005). Educating the world's children: Patterns of growth and inequality. Washington, DC: FHI 360.

World Bank. (2015). World Development Indicators. Retrieved from http://data.worldbank.org/country/tanzania 